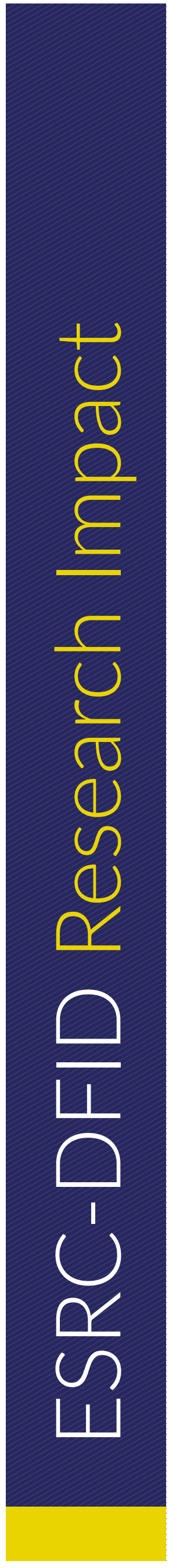

\title{
COMMUNITIES IMPROVE WATER MANAGEMENT IN BURKINA FASO
}

Globally, water scarcity and poor water quality have a major impact on food security and livelihoods. While there has been significant progress in the past decade, and over 90 per cent of the world's population now has access to clean drinking water, there is still a long way to go to reach the most marginalised and ensure that water is protected from degradation. The set-up of 'Innovation Platforms' in Burkina Faso around two small water reservoirs meant that diverse members of rural communities, agricultural agents, and NGOs could reconcile differences and manage their most precious resource in harmony.

\section{THE CHALLENGE}

Burkina Faso is one of the world's poorest countries, with a high dependence on agriculture for its economy. Natural disasters and adverse weather conditions mean that sustaining a livelihood in rural areas beyond a single season is difficult and often incredibly contentious. In Boulgou, a province in the Centre-East region of Burkina Faso, 16 villages rely on two water reservoirs for their livelihoods. This is especially true in the dry season when there is little water. But with many people using it for different purposes, including herders, fishers and horticulturalists, conflicts and misunderstandings undermined the governance of the water.
Water Management Committees were set up by the state, including local and state actors such as village chiefs and deputies to oversee the management of the reservoirs. Yet in reality, the elder men farmers representing the local communities could not represent the views and lives of the whole community, including poor women, herders, and fishermen from a different ethnicity.

\section{THE RESEARCH}

The ESRC-DFID-funded project 'Pathways out of poverty for Burkina Faso's reservoir-dependent communities' created Innovation Platforms (IPs) - spaces for face-to-face learning, exchange, and negotiation.

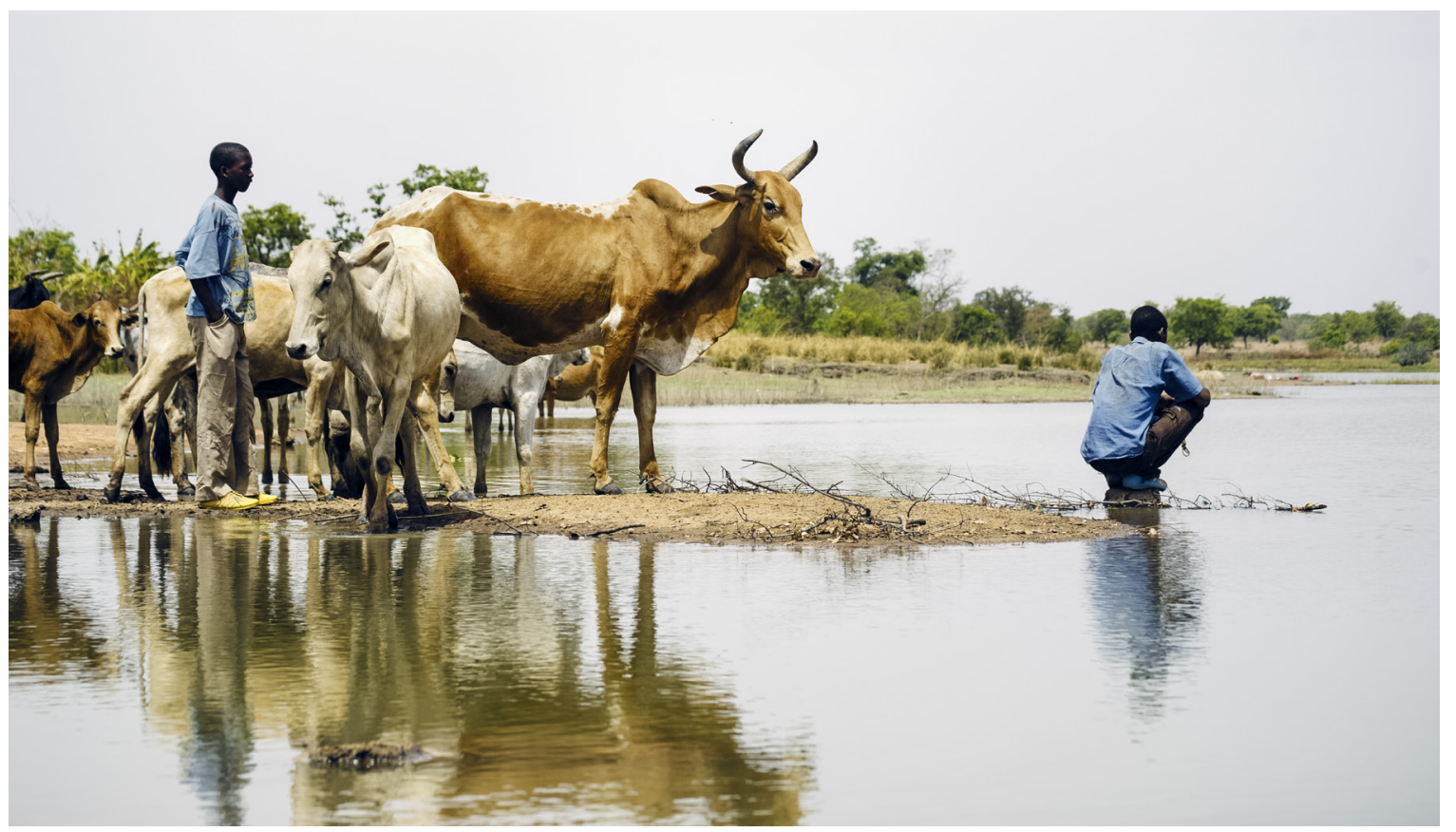

Cover photo: Youths watch over their cattle at a reservoir, often the last water point during the hottest and dryest months of the year, Burkina Faso. Credit: Ollivier Girard/CIFOR/Flickr licensed under CC BY-NC-ND 2.0 
The project supported communities, state and nonstate actors (NGOs) to participate in several meetings and discussions to enhance management of water and make it more equitable.

Communities came together during 2018 to discuss the problems and prioritise solutions around managing small water reservoirs. Participants worked within peer groups, i.e. elder men, younger men, women, and state and NGO actors, and then came together in plenary. This process showed many of the root causes for the drop in water quality and quantity and for tensions, which included the application of fertilisers by some, overfishing, and herders trampling farmers' crops when bringing their animals to drink.

Together they set out a clear action plan to create an inclusive community governance committee to manage the reservoir, to increase the height of the dykes and rehabilitate the reservoir channels, and to train the communities around a sustainable action plan.

\section{THE IMPACT}

Women are now much more involved in the reservoir management process than they had been before.

For example, as a mainstay of women's livelihoods, growing vegetables adjacent to the reservoir was very contentious as there was not enough land for everyone and residents were concerned that it caused a drop in the reservoir's water level. Despite the high stake that vegetable growers had in managing the reservoir, women were not included in discussions or in decision-making committees. Through the platforms, the importance of women's participation in reservoir management has been recognised, and they have created a sub-group to advise a new water users' committee.

It has also been recognised that young people have an important role to play to bring about change in the future. As a result of the project, young men have taken up roles as president and vice president in one of the committees. Furthermore, a Fishermen's Association has been created, and 2018 was the first year that the fishermen have respected 'fishing blackouts' and not used small meshed nets that capture immature fish. Herders are now using livestock corridors to avoid damaging farmers' crops.

The communities have also rallied and raised funds to realise some of the solutions that they have identified. For example, they hired professionals to unblock a main channel to improve flow into the reservoir and invited state water technicians to provide guidance throughout the process.
As a regional agricultural extension agent, Kyelem Richard, explained, 'There is a good collaboration with communities. We understand each other better and they are coming to me to involve me in their activities and ask for advice'. This is a change from communities viewing state actors as policing a situation to seeing them as a supportive voice.

In striving to achieve Goal 6 of the Sustainable Development Goals - Ensure access to water and sanitation for all - this project clearly recognises the need to 'support and strengthen the participation of local communities in improving water and sanitation management'.

\section{FURTHER READING}

Elias, M. et al. (2018) 'Pathways out of Poverty for Burkina Faso's Reservoir-Dependent Communities', presented at the 'Power of Partnership' Conference, New Delhi, India, 3-5 December, https://cgspace. cgiar.org/bitstream/handle/10568/99306/Bioversity WaterBF.pdf (accessed 13 February 2019)

Jones, S. and Elias, M. (2018) 'Searching for Pathways towards Equitable and Sustainable Reservoir Management, Bioversity International, 27 February, www.bioversityinternational.org/news/detail/ searching-for-pathways-towards-equitable-andsustainable-reservoir-management/ (accessed 13 February 2019)

Policy Support in Water, Environment and Conservation Management (2018) 'Using WaterWorld and Co\$ting Nature to Understand Current and Future Ecosystem Services in the Volta Basin', 28 February, http://blog.policysupport.org/2018/02/ using-waterworld-and-coting-nature-to.html (accessed 13 February 2019)

Pathways out of poverty for Burkina Faso's reservoirdependent communities

The research team was funded by ESRC-DFID's Joint Fund for Poverty Alleviation Research and included Bioversity International, SNV World, King's College London, and the University of Ouagadougou.

\section{THE IMPACT INITIATIVE}

\section{For International Development Research}

The Impact Initiative seeks to connect policymakers and practitioners with the world-class social science research supported by the ESRC-DFID Strategic Partnership, maximising the uptake and impact of research from: (i) the Joint Fund for Poverty Alleviation Research, and (ii) the Raising Learning Outcomes in Education Systems Programme. We seek to identify synergies between these programmes and their grant holders, support them to exploit influencing and engagement opportunities, and facilitate mutual learning. The Impact Initiative is a collaboration between the Institute of Development Studies (IDS) and the University of Cambridge's Research for Equitable Access and Learning (REAL) Centre.

\section{CREDITS}

This impact story was written by Vivienne Benson as part of the Impact Initiative Communications team based at the Institute of Development Studies, UK in collaboration with Dr Marlène Elias, Bioversity International and Aurokiatou Traoré, SNV World, The Netherlands.

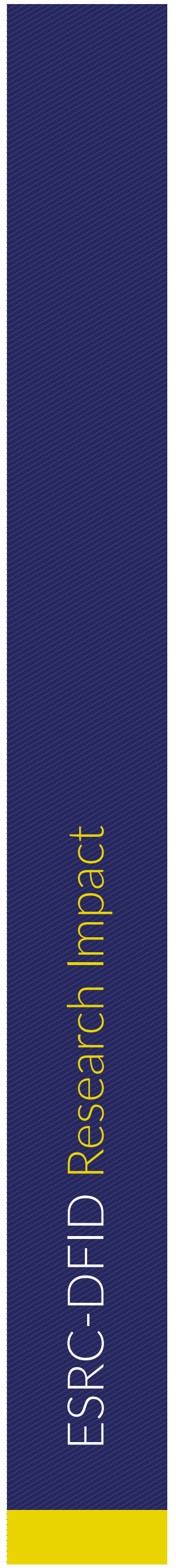

